مجلة كلية التربية الرياضية - جامعة بغداد ** المجلد الثلاثون* العدد الثاني * لسنة

$r \cdot 1 \Lambda$

\title{
الامداد بمضادات الاكسدة وتأثيره بتركيز الكولاجين في دم الماتجات رباعي المنتخب الوطني لرفع الاثقال
}

م.م. عمر خالا ياسر

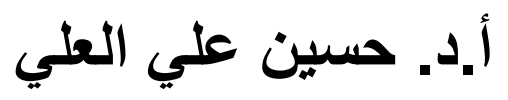

\section{A $1 \leqslant q q$}

\section{مستخلص البحث باللغة العربية.}

هدف البحث إلى أعداد برنامج للأمداد بمضادات الاكسدة من نوع (Antioxidant Ultimate Nutrition)

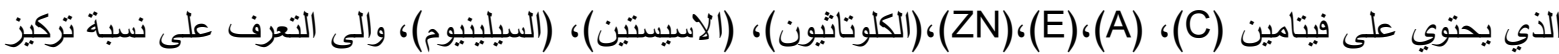
نسبة الكولاجين في دم الرباعين، والى التعرف على تأثير الأمداد بمضادات الاكسدة في مؤشر الكولاجين لعينة البحث. فكانت العينة من رباعي المنتخب الوطني فئة منقدين، وآستخدم الباحث المنهج التجريبي ذي تصميم المجموعة الواحدة التجريبية ذات الإختبارين القبلي والبعدي لملاعهنه طبيعة المشكلة، وكان أختبار العينة بالطريقة العمدية، وأستغرقت مُدة التجربة شهرين، وآستخدم الباحث الحقيبة الأحصائية(SPSS)، وقد نت عرض النتائج وتحليلها ومناقثتها، وأستتتج الباحث بأن الامداد بمضادات الاكسدة كان لها تأثثر معنوي في مؤشر الكولاجين بين الاختبارين القبلي والبعدي (قبل الجهد وبعد الجهد). وأوصى الباحث عمل فحوصات الدم الدورية الى الرياضين لمراقبة التغير الحاصل في المؤشرات البيوكيميائية لغرض السلامة الصحية للرياضين. وكذلك الامداد بمضادات الاكسدة الى الرياضين في فعاليات مختلفة فبل التدريب وبعده لارتقاء بمستوى الرياضي من ناحية المؤشرات البيوكيميائية. واوصى الباحث ايضا بزيادة المدة الزمنية لعمل التجربة للحصول على تطور أفضل في متغيرات البحث وخصوصاً مع عينات من مستوى عالٍ.

\section{Abstract.}

\section{Antioxidant Supply and Its Effect On Concentration Of Collagen In National League Weightlifters' Blood}

The aim of the research is to design a program for the supply of Antioxidant Ultimate Nutrition which contains vitamin C, A, , E, Z, Glutathione (GSH), Selenium as well as identifying collagen concentration ratio in the blood of weightlifters. The researcher used the experimental method. The subjects were national league weightlifters. The experiment lasted for two months. The data was collected and treated using (SPSS). The researcher concluded that the supply of antioxidants had a significant effect on the collagen index in pre 


\section{مجلة كلية التربية الرياضية ـ جامعة بغداد ** المجلا الثلاثون ** العدد الثاني ** لسنة}

$r \cdot 11$

and posttests (before and after effort). The researcher recommended making regular blood tests for athletes to monitor the change in biochemical indicators and for the health of athletes. The researcher recommended providing supply of antioxidants to athletes in various activities before and after training to upgrade the level of athlete in terms of biochemical indicators and increasing the period of the experiment to obtain better development in the research variables, especially with samples of high level.

Keywords: antioxidants, collagen concentration, weightlifters.

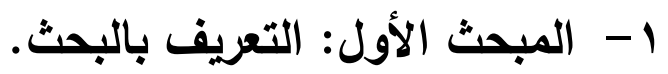

1 - 1

أدى النطور التكنولوجي في جميع ميادين الحياة بصورة عامة والرياضة بصورة خاصه الى اكتثاف العديد

من النواحي الايجابية لمصلحة التدريب الرياضي والارتقاء به الى أعلى المستويات، والتركيز على هذه النواحي الايجابية وإهمال ما يمكن أن يؤثز بصورة سلبية على تحقيق الانجاز، وهذا ناتج عن تداخل العلوم فيما بينها من أجل تحسن مستوى الرياضي والانجاز بشتى أنواعه.

تعد ممارسة الجهد البدني ذات فائدة كبيرة للفرد بصورة عامة وللرياضي بصورة خاصة من خلا الانظظام

بالتدريب المقنن سواء في عمليات الاستجابة أو التكيف من خلال الجهد البدني الممارس. وعلى الرغم من كل التأثرات الايجابية للأنشطة الرياضية ألا أن هنالك بعض المصادر والدراسات العلمية اثارت الى وجود أثنار سلبية للأنشطة البدنية المكثقة والعنيفة من خلال عمليات الايض المصاحبة لهذه الانثطة مؤدية الى تلف الانسجة، وهذه العملية تمثل الاثار الجانبية للجه البدني المبذول خلال الاداء الحركي وخاصة للمستويات العليا، لأنها تركز على الاحمال البدنية عالية الثندة وذات المجهود البدني المضني والكبير، مما يشير الى الحاجة الى اجراءات وعوامل عديدة يمكن اتباعها لعودة الجسم الى ما كان عليه قبل الجهد وأفضل من ذلك.

وتعد مضادات الاكسدة واحدة من العوامل التي تساهم في مقاومة التلف العضلي، وهذا بدوره هو ناتج طبيعي لعميات الأيض بعد التدريب للشخص الطبيعي، وكذلك يمكن أن تأتي من التلوث البيئي والغازات المستتشقة من المحيط الخارجي.

من هنا تأتي أهمية هذا الموضوع فهو بالنسبة للباحثين مجال خصب للبحث والدراسة، للقيام بإجراءات مختلفة للحد من نتائج التلف العضلي المترتبة من هذا الجهد البدني العالي ومن هذه الاجراءات، أعداد برنامج للأمداد بمضادات الاكسدة والتي سوف نتعرف من خلاله على تأثير الامداد بمضادات الاكسدة في اعادة بناء الانسجة أو الاقلال من تلفها الذي يمكن أن نكثفه ونتعرف عليه من خلال التغير في نسبة الكولاجين في الدم الذي يدل على التلف العضلي، 
مجلة كلية التربية الرياضية - جامعة بغداد ** المجلد الثلاثون * العدد الثاني ** لسنة

$r .11$

فإهمال المعرفة سوف يؤدي إلى صعوبة أعداد البطل الرياضي، والى قصر عُمرَ الانجاز للرباع من ناحية المستوى،

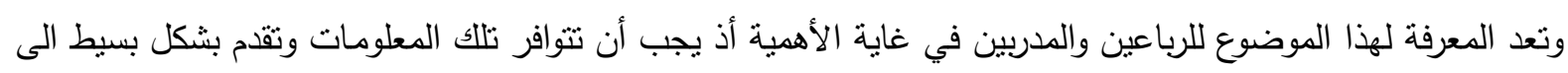
كافة ممارسي فعالية رفع الاثقال حفاظا على حالتهم الصحية وانجازاتهم الرياضية.

\section{r-1}

ظهرت المشكلة لدى الباحث وهي افتقار جيع الاتحادات الرياضية العراقية ومنها اتحاد رفع الاثقال الى مختبر طبي علمي يختص بحالة الرباعين، لأن من أولويات الانجازات العالمية في جميع الفعاليات في دول العالم المتطورة هي المتابعة الطبية الدقيقة الى جميع الرياضين وفحصهم دورياً للتأكد من سلامتهم لأن صحة الرياضي أهم من كل الثيء، وكذلك للأهمية مصاحبة البرامج التدريبية بالمكملات الغذائية ودورها الفعال في استشفاء الرباعين.

$$
\text { : r }
$$

ا ـ التعرف على نسبة تركيز نسبة الكولاجين في دم الرباعين.

r. أعداد برنامج للأمداد بمضادات الاكسدة من نوع(Antioxidant Ultimate Nutrition) الذي يحتوي على

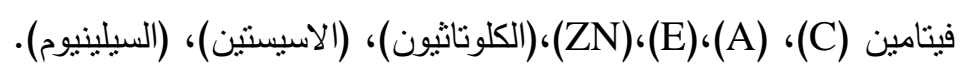

r. التعرف على تأثير الأمداد بمضادات الاكسدة في مؤشر الكولاجين لعينة البحث.

$$
\text { | }
$$

• وجود فروق معنوية بين الاختبارات القبلية والبعدية في مؤشر الكولاجين ولصالح الاختبارات البعدية لعينة

$$
\begin{aligned}
& \text { البحث. } \\
& \text { 1-0 مجالات البحث: }
\end{aligned}
$$

• الكولاجين (Collagen): هو عبارة عن بروتين يتواجد في أنحاء متعددة من الجسم، حيث يتواجد بشكل أساسي

في الأنسجة الضامة الليفية (Connective Tissues) الموجودة في الجلد، والعضلات، والعظام، والأسنان،

والأظافر ، والأربطة، والأوتار، والغضاريف، حيث يعتبر الكولاجين المكون الأساسي لهذه الأنسجة الضامة. 
r- - ب - المبحث الثاني: الدراسات النظرية.

r - الخصائص البيوكيميائية للعضلة:

في بادئ الامر وقبل الخوض في الخصائص البيوكيميائية نتعرف على العضلة وما هي، (العضلة) هي نسيج ليفيّ يتميز بقابلية الانقباض والانبساط ويؤمّّن حركة الكائن .وتتكون العضلة الهيكلية من حزم عضلية وكل حزمة تتكون من عدة ألياف عضلية ويسمى سيتوبلازم الليفة العضلية بـ الساركوبلازم وغثاء الليفة العضلية يسمي الساركوليما وتتكون الليفة العضلية من ليفات عضلية والليفة الواحدة تتكون من قطع عضلية تكون متجاورة والقطع العضلية تتكون من خيوط بروتينية وهي أكتين وميوسين. تتقسم العضلة إلى ثلاثة أقسام، وهي العضلة هيكلية مخططة وهي عضلات تتكون من حزمة من الألياف الرفيعة مثل عضلات الرأس والجذع والأطراف وهي تتيح الحركة وتسمى عضلات إرادية، وعضلة ملساء وهي تتكون من خلايا أو ألياف مسنطيلة وهي غير منصلة بالهيكل العظمي مثل العضلات المخططة وهي تحيط بالأعضاء المجوفة منل الأمعاء والقصبة الهوائية والأوعية الدموية وتسمى عضلات لا إرادية و عضلة القلب وهي أيضاً عضلة غير إرادية ولكنها أقرب في البنية إلى العضلة الهيكلية، وتوجد فقط في القلب. (9) (

\section{r r r r التلف العضلي الناتج عن الأداء البدني:}

تظهر الدراسات المنشورة الاختلافات في الاستجابة الفسيولوجية بين التدريبات البدنية التي تعمل على إطالة العضلات وتلك التي تعمل على قصرها، وبالنظر إلى مقدار متكافئ من الحمل البدني فأن تدريبات تقصير العضلات تتطلب طاقة أعلى كما هو واضح من الاستهلاك الأكثر للأكسجين، وكذللك فإنه قد لوحظ استدعاء عدد اقل من الوحدات الحركية أثناء تدريبات استطالة العضلات، ومن ثم فهي تتطلب قدرا أقل من الطاقة لتؤدي نفس العمل الذى يتطلبه التدريب بالنقصير للعضلات. كما أن حداً أقصى من القوة أكبر يمكن الحصول عليه من تدريبات الاستطالة، عن ثلك المتولدة في تدريبات تقصير العضلات وهذا يؤدي في النهاية إلى حدوث تعب عضلي أسرع أثناء تدريبات الاستطالة

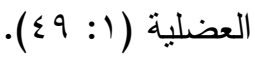

على النقيض فقد لاحظ آخرون أن بداية الإحساس بالألم العضلي يتأخر في التدريبات المطيلة للعضلات

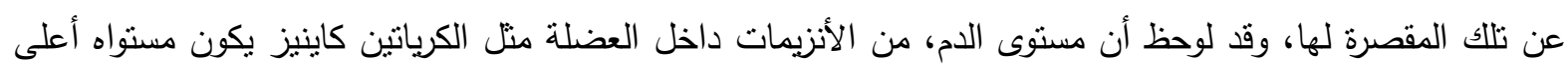
في التدريبات المطيلة للعضلات عنه في تلك المقصرة لها، وقد تم ايعاز ذللك إلى التوتر الأعلى في ألياف العضلات، والعدد الأقل المستدعي للعمل من هذه الألياف في التدريبات المطيلة عنه في الألياف بالتقصير للعضلات (• (: ب؟7). أن أعلى معدل من تلف العضلات بعد التدريبات المطيلة يمكن ملاحظته خلال ثلاثة أيام أو أطول من توقيت الأداء، وهو ما يمكن أن يكون بسبب التمزق الميكانيكي الموجهة على هذه الألياف، وكذلك قد يعزى إلى الاستجابة الالتهابية والى زيادة إنتاج الجذور الحرة، وهو ما يطيل عمر التلف لأيام عديدة بعد التدريب، فنرى استدعاء الخلايا 


\section{مجلة كلية التربية الرياضية - جامعة بغداد * المجلد الثلاثون ** العدد الثاني ** لسنة}

$r+11$

المناعية المتعادلة خلال القليل من الساعات بعد التلف العضلي وتطلق هذه الخلايا الجذور الأكسجينية الحرة والسموم الأخرى التي تؤدي إلى زيادة سيولة و نفاذية الأغشية الخلوية، وتستبدل هذه الخلايا بالخلايا المناعية أحادية النواة والتي تتحول إلى الخلايا المناعية المستقرة الملتهمه والتي تطلق سموم أخرى كما تعمل على التهام النسيج التالف وتؤدي هذه الخلايا في النهاية إلى تتشيط التأم هذا التلف عن طريق تتشيط الخلايا القاعدية في العضلات، حيث يؤدي التغير في الغشاء الخلوي وغشاء الثبكة الساركوبلازمية إلى تحرر الكالسيوم والذي بدورة ينشط العديد من آليات إصلاح التلف في العضلات، عن طريق تحفيز العديد من الأنزيمات المحللة للبروتين والدهون الغشائية، ويصل معدل تحرر هذه الأنزيمات والسموم والجذور الحرة إلى أقصاها خلال عدة أيام بعد التدريب، متوازية مع بدء إعادة البناء من الألباف التالفة، ويؤدي هذا التلف وخاصة تحرر جذور الأكسجين والدهون الحرة إلى التكيف العضلي بزيادة كفاءة الآليات المضادة للأكسدة الأنزيمية، ومحتوى الخلايا من الكلوتاثيون، ولكن محتوى العضلات من الفيتامينات مضادة الأكسدة قد يتتاقص إذا لم يكن هناك إمداد جيد منها في الغذاء أو المكملات الغذائية، ومع ذلك فإن الدراسات المتعلقة بإمداد الجسم بمضادات الأكسدة المختلفة تبين كفاءة منضاربة لمثل هذا الإمداد ولكنها جميعا تشترك في إيضاح أن هذا الإمداد له فعل إيجابي على سرعة الثفاء، ومن هذا المنطلق يجب ان نراعى فترة الاستشفاء بعد التدريب لإتاحة الفرصة الاكبر لعمليات ترميم التلف الذي حدث في الالياف العضلية بسبب التدريبات عالية الثندة، واتاحة فرصة الوصول الى مرحلة التعويض الزائد، وهنا نكمن اهمية استخدام النظام الغذائي كوسيلة للاستشفاء والاعتماد على زيادة مضادات الاكسدة في وجبات الرياضين الغذائية أو التعويض عنها بالمكملات الغذائية الغنية بمضادات الاكسدة. (1)

من أهم مؤشرات التلف العضلي هو (الكولاجين، المايوكلوبين، كرياتين كاينيز (CK) (r ا: .1 ( ).

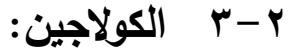

الكولاجين بعدّ الكولاجين نوعاً من أنواع البروتين الليفي، وينتكّل من مجموعة من الأحماض الأمينية التي

تُصنع داخل الجسم، ويدخل الكولاجين في تركيب غالبية الأنسجة، وهي المادة التي تعتمد عليها الانسجة الضامة، ويشارك في معظم الانسجة و تصل بين الأوتار والأربطة والمفاصل والعضلات والثعر والجلد والاعضاء الحيوية. وبروتين الكولاجين ينتج في جميع أنحاء الجسم ويقدم القوة والدعم الى الالياف وتصبح قوية، ويربط أعضاء الجسم معا

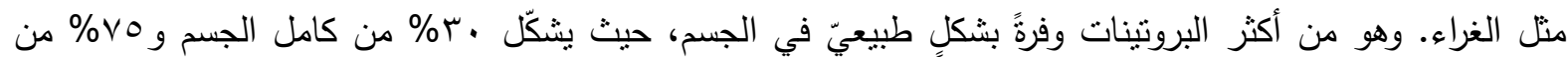
الجلد، إلّا أنّه ومع التقدّم في العمر يقلّ إنتاجه في الجسم، مما يؤثر سلباً على قدرة الجسم على إصلاح وتجديد نفسه، مما يتسبب نهايةً في حدوث تغيّرات في المظهر، والمرونة، والقوّة والوظيفة. تبعاً لما ذُكر سابقاً، فإنّ قدرة الجسم على ئى إنتاج الكولاجين تقلّ بمعدّل ه. 1\% سنوياً بعد عمر الخامسة والعشرين، وتُصبح ألياف الكولاجين هثّة وضعيفة، مما يتسبب في إضعاف الأنسجة الضامّة المسؤولة عن تماسك الجلد، كما يحدث ارتخاء في العضلات الدقيقة. وهذا له أثز سلبي على قدرة الجسم على إصلاح وصيانة نفسه، مما يؤدى في نهاية المطاف إلى تغيرات في المظهر، والمرونة، 
مجلة كلية التربية الرياضية - جامعة بغداد ** المجلد الثلاثون * العدد الثاني * لسنة Y. IN

والقوة، والوظيفة. وإلى جانب العديد من خصائصه البنيوية، الكولاجين هو المسؤول عن الإصلاح والنمو في معظم أنسجة

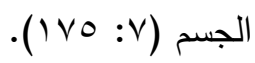

\section{r-r- r بوائد الكولاجين الصحية:}

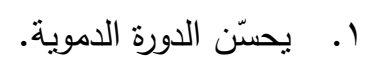

r. يعزّز التئام الجروح، يساهم الكولاجين في المحافظة على صحة و قوة الأسنان و اللثة من خلال دعمهما بكمية وافرة من البروتين من خلا التكوين الداخلي لكل منهما بشكل أسرع من الشكل طبيعي، وهذا ما يفسر التفاوت

$$
\text { r. يحدّ من آلام التهاب الآلتئام الجروح من شخص الى أخر. }
$$

ع. يقوم الكولاجين بتجديد خلايا الجلد في جميع المراحل العمرية، إلا أن يبدأ الثخص في التقدم بالعمر، وعندها يصبح انتاج الكولاجين في تناقص، و هذا ما يفسر ظهور التجاعيد و ترهل بعض مناطق الجلد لدى الكبار في

$$
\text { العمر . }
$$

0. فوائد الكولاجين الجمالية: ومنها يعزّز نموّ الثعر • يؤخر ظهور التجاعيد، يُحافظ على مرونة البشرة، ويعطيها المظهر الثبابيّ، يتخلّص من الخيوط البيضاء في الجسم، يرقّق وينعم البشرة، يُعطي الثنفاه والخدود مظهراً

$$
\text { أكثر امتلاءً. }
$$

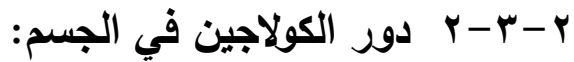

يشكل الكولاجين نسبة •r\% من البروتين الذي يحتاجه الجسم، و يكؤن نسبة ثلاثة أرباع التركيب العضوي للجلد، كما أن الكولاجين يتميز بمجوعة كبيرة من الخصائص و الميزات البنيوية، المعنية في ترميم و نمو أغلب الأنسجة الحيوية في الجسم.

r-r-r r r أسباب نقص الكولاجين:

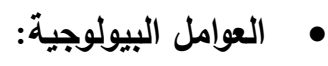

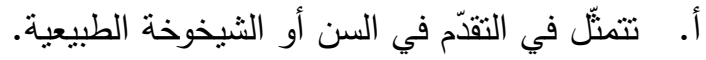

$$
\text { ب. التغيّرات الهرمونية. }
$$

ت. ضعف عمليات التمنيل الغذائيّ.

العوامل البيئية:

أ. تتمتل في التعرّض المستمر لأشعة الثمس فوق البنفسجية.

ب. ب. المياه المعالجة بالكلور .

ت. السموم البيئية أو تلوّث الجو. بلون 


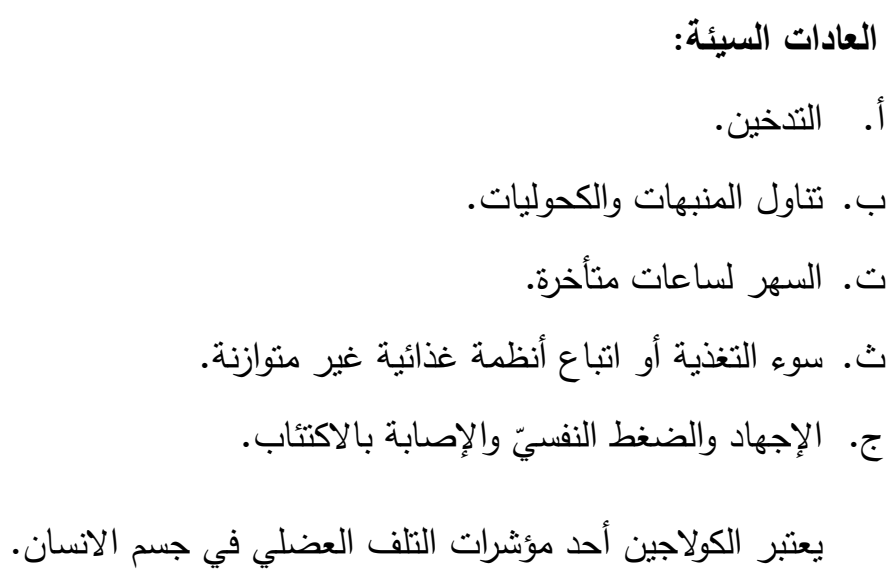

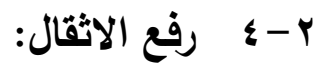

هي رياضة أولمبية يقوم بها المشاركون ويطلق عليهم الرباعون بأداء رفتنين الأولى

تسمى الخطف والثانية نتز ·

هناك اختلاف بين رفع الأثقال والتدريب بالأثقال وتدريبات القوة، بمقارنة تدريبات القوة التي تختبر حدود

القوة القصوى للمتدرب (مع أو بدون مساعد)، تمرين رفع الأثقال يختبر القوة الانفجارية والحركة الانفجارية مثل الحركتان

الخطف والنتر ويجب تطبيقهما بشكل سريع معا وتحكم بالوزن بسبب المسافة الذي سوف يقطعها الثقل خلال التطبيق.

كل متنافس يحظى بثلاث محاولات للخطف وثناث محاولات للنتز والفائز هو الذي يحصل على المجموع

الاكبر من مجموع المحاولات التي قام برفعها (الخطف+النتر = X)، كل محاولة يتم تقييمها بواسطة ثلاث حكام (علم

أبيض ومعناه أن المحاولة جيدة، علم أحمر ومعناه محاولة ملغية، أو "لا تحسب") المحاولة الجيدة هي التي تحصل على له عدد ثلاث أعلام أو علمين من الحكام وسوف نتطرق هنا الى فعالية الخطف والنتر بالتقصيل.

\section{r- - المبحث الثالث: منهج البحث واجراءاته الميدانية. \\ r-}

المنهج هو "اتناع خطوات منطقية معينة في تتاول المشكلات الظاهرة أو معالجة القضايا العلمية للوصول

الى اكتثاف الحقيقة" (ج: V • (1). وأن طبيعة المشكلة المراد دراستها تحدد منهجيه البحث، وعلى هذا الاساس أستخدم الباحث المنهج التجريبي ذات المجموعة التجريبية الواحدة ذات الاختبارين القبلي والبعدي لملائمة طبيعة المشكلة، اذ يعد المنهج التجريبي من "أكثر الوسائل كفاية في الوصول الى معرفة موثوق بها". 


\section{مجلة كلية التربية الرياضية - جامعة بغداد ** المجلد الثلاثون * العدد الثاني * لسنة}

\section{$r+11$}

بغية القيام بخطوات البحث وتتفيذه بشكل علمي، نم اختيار العينة بالطريقة العمدية من رباعي المنتخب

العراقي لرفع الاثقال البالغ عددهم (V) رباعين فئة متقدمين، وتم اختيار جميع الرباعين كعينة للبحث وبذلك أصبحت عينة البحث تمثل المجتمع بنسبة . . 1\%، وتألفت العينة من الفئات الوزنية الاتية (فئة جه رباع واحد، فئة بآ رباع واحد، فئة

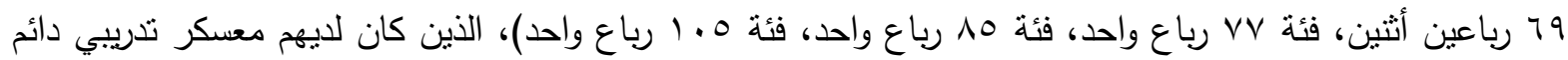
في بغداد، قاعة التأميم الرياضية - شارع فلسطين، استعداداً للبطولة الدولية (التضامن الاسلامي) التي أجريت في مدينة (باكو) في أذربيجان بتاريخ (11)

\section{r-r ب و وسائل جمع المعلومات والادوات والاجهزة: ب-r}

\section{1. المصادر والمراجع العربية والاجنبية".}

أعتمد الباحث على المصادر العربية والاجنبية المتوفرة بمكتبات الجامعات العراقية للاستفادة منها

خلال الدراسة.

$$
\text { • المقبة المعلومات الدولية (الانترنت). }
$$

• أجرى الباحث عدد من المقابلات الثخصية مع الخبراء والمختصين في مجال مؤشرات الدراسة، وذللك للآخذ بآرائهم العلمية التي تخدم الدراسة وللوقوف على أهم الخطوات الاساسية للإجراء البحث.

$$
\text { r-r-r الاجتمارة تسجيل. }
$$

\section{* المصادر والمراجع العربية والاجنبية} • أبو العلا عبد الفتاح، عمر شكري عمر، طارق حسن المتولي. الاداء الرياضي الامن والثقوق الطليقة، مضادات الاكسدة ،

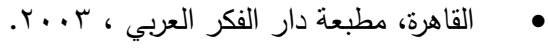

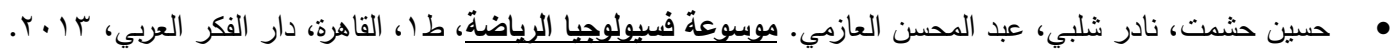
أبو العلا عبد الفتاح، عمر شكري عمر، طارق حسن المتولي. الاداء الرياضي الامن والثققق الطليقة، مضادات الاكسدة ، القاهرة،

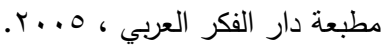
• أبو العلا عبد الفتاح. الاستثفاء في المجال الرياضي ،طا القاهرة، مطبعة دار الفكر العربي ، 1999.

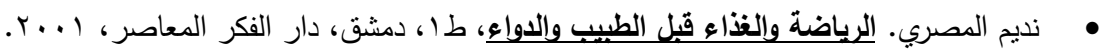

** * ا. الطبيب الدكتور يعقوب محمد مدير مختبرات السموم في مستشفى مدينة الطب. r. أ.د بري حبيب سيف الله كلية العلوم قسم الكيمباء الحياتية في جامعة بغداد. r. أ.د علي شبوط كلية التربية البدنية وعلوم الرياضة جامعة بغداد. ع. أ.م.د مصطفى صالح كلية التربية البدنية وعلوم الرياضة جامعة بغداد، رئيس أتحاد رفع الاثقال غرب أسيا. 0. أ.م.د زيزفون نبيل نصيف كلية العلوم قسم الكيمياء في الجامعة المستتصرية. 
1. (Centrifuge) ( جهاز الطرد المركزي

r. آ. ميزان دقيق جداً للمواد الكيميائية نوع (Sartor).

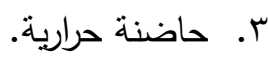

ع. ساعة توقيت نوع (Diamond). 0. حافظة تبريد (Box) لحفظ العينات. T. عدة التثخيص (Kit) للكثف عن الكولاجين. V V. دوارق وبكرات وماصات زجاجية ومواد تحضيرية كيميائية مختلفة.

$$
\text { ^. } 1 \text { ^. . أنايبب زجاجية(Tube). }
$$

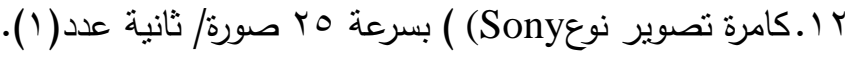
rا ا.شفتات حديد (بار) وزن (·rكغم) و أقراص (أوزان) متعددة الاوزان.

$$
\text { r- r- }
$$

$$
\text { قياس الكولاجين العضلي (Collagen): }
$$

تقدير تركيز المايوكلوبين بجهاز كروموتوغرافيا السائل عالي الاداء:

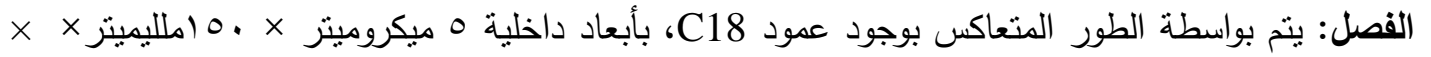

$$
\text { T. } 4 \text { ملليمتر }
$$

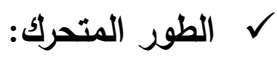

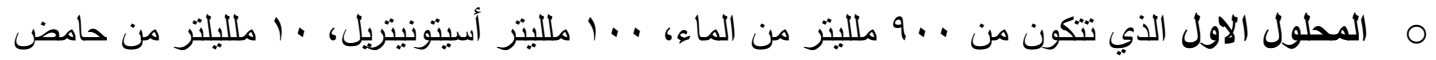

$$
\text { ترايفلورواسينيك) }
$$

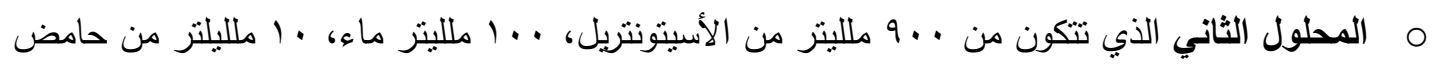

$$
\text { ترايفلورواسينيك) }
$$

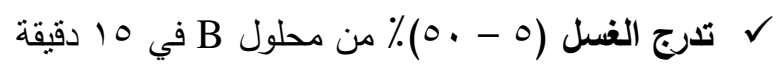

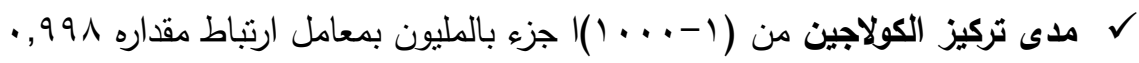

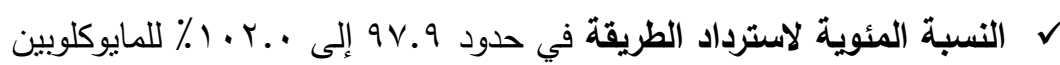




\section{مجلة كلية التربية الرياضية - جامعة بغداد ** المجلد الثلاثون ** العدد الثاني ** لسنة}

$r \cdot 11$

لالدة يعكسها الانحراف المعياري النسبي ستة مكررات حقنت داخل الجهاز للمايوكلوبين بمستويات نراكيز

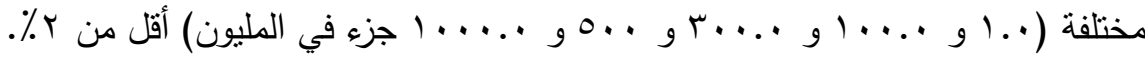
محدودية الطريقة للكولاجين منخفضة مما يتيح تقدير الكولاجين في تركيز منخفض.

\section{ب-ه الاختبارات القبلية:}

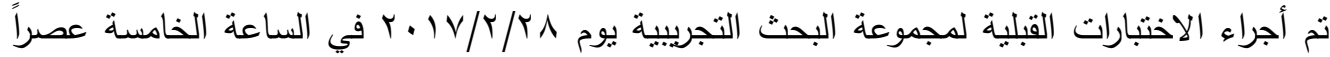
(اختبارات قبل الجهد) وفي الساعة السابعة وعشرون دقيقة (اختبارات بعد الجهد)، ، وذلك في قاعة التأميم، وتم أجراء الاختبار من قبل كادر متخصص، وتم أجراء الألية العلمية لحفظ الدم حتى قياس المتغيرات، وسعى الباحث الى تدوين جميع الظروف في أثثاء هذه الاختبارات من حيث الزمان والمكان وطريقة العمل وفريق العمل المساعد وطريقة تتفيذ نسلسل الاختبارات بغية خلق الظروف نفسها أو ما يثابها عند أجراء الاختبارات البعدية.

$$
\text { وجرى هذا الاختبار على مرحلتين: - ( }
$$

\section{أ- ق قبل الجهد:}

تم سحب الدم من أفراد عيمة البحث مساءاً في الساعة الخامسة عصرا وقبل أداء أي جهد (في حالة الراحة) وذللك بالنداء على الرباع بعد تسجيل أسمائهم والمعلومات الخاصة بهم من (العمر البيولوجي، العمر التدريبي، الوزن، الطول) يجلس الرباع على الكرسي ويمد أحدى ذراعيه، ويقوم الطبيب المختبري بلف رباط ضاغط في منطقة العضد ليتم حصر الدم الوريدي العضدي عندها يقوم بتعقيم منطقة صغيرة من الوريد ويغرس الحقنة في الوريد منطقة المرفق والمباثرة بفتح الحزام الضاغط لمرور الدم ويبدأ بسحب الدم بمقدار (0 سي سي) وهي كمية كافية بالنسبة الى متغير البحث، بعدها يقوم الطبيب المختبري بسحب الحقنة من ذراع الرباع ويعقم المنطقة، ثم يفرغ الدم من الحقنة في أنابيب مخصصة مكتوب عليها أسم الرباع وقبل الجهد، تجمع أنابيب الدم لأفراد العينة وتوضع في حافظة

بعد الانتهاء من الوحدة التدريبة للرباعين بـ ·r دقيقة تم سحب الدم من كل رباع وتتكرر إجراءات سحب الدم نفسها قبل الجهر وتوضع في أنابيب مكتوب عليها أسم الرباع بعد الجهد وتحفظ هذه الانابيب في حافظة

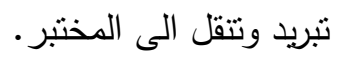

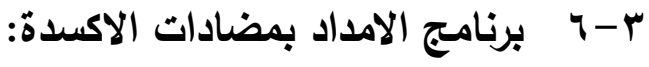

بعد التتسيق مع الاتحاد المركزي لرفع الاثقال وحصول الموافقة لأجراء تجربة البحث على المنتخب العراقي وذلك لأهميتها، قام الباحث بأجراء الاختبارات القبلية التي تتكون من اختبارين، اختبار قبل الجهد البدني واختبار بعد 
الجهد البدني أي (بعد الوحدة التدريبية) بـ ·r دقيقة، وعدَ الباحث برنامج للأمداد بمضادات الاكسدة من نوع لمدة شهرين بواقع ثمانية اسابيع معتمدا في ذلك على التعليمات الخاصة (Antioxidant Ultimate Nutrition) للمنتج والمدونة على العلبة وكذلك أراء المختصين في مجال التغذية والمكملات الغذائية، وهو أمداد الرباعين بمضادات الاكسدة قبل الوحدة التدريبية بـ ب ساعات بـ قرص واحد حجم .. .7 ملغم، وحسب شروط (FDA) منظمة الغذاء والدواء الامريكية، وقد طبق هذا البرنامج خلال المعسكر التدريبي للمنتخب الوطني العراقي لرفع الاتقال استعدادا لبطولة التضامن

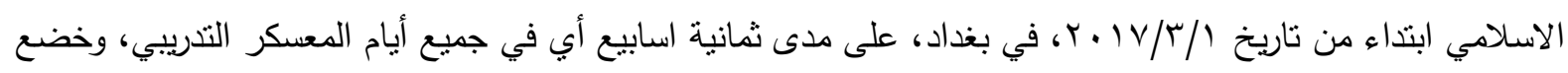

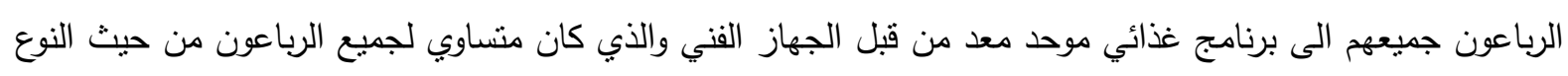

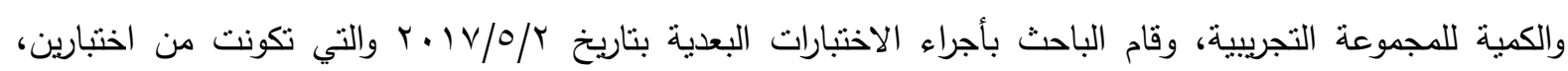

اختبار قبل الجهد البدني واختبار بعد الجهد البدني أب (بعد الوحدة التدريبية) بـ •ـ دقيقة.

\section{• وصف المنتج كما موجود على العلبة والموقع الاكتروني للمنتج:}

توفر مضادات الأكسدة طبقة من الحماية للخلايا والأنسجة في الجسم. على وجه التحديد حماية ضد

ضرر الجذور الحرة. وأن الانسان يتتفس الأكسجين لغرض العيش. والأكسجين ضروري لجميع وظائف الجسم الأساسية. ومع ذلك، فإن كمية صغيرة من الأوكسجين بهرب من الكترون خلية الانسان وينتج منتجات ثنانوية غير مستقرة تسمى الجذور الحرة. وان العمليات التي تحدث داخل الجسم منل التمنيل الغذائي، وكذلك العوامل خارجية ترتبط بالبيئية، يمكن كذلك أن تتتج الجذور الحرة. أن الجذور الحرة في الجسم بمكن أن نسبب تلفاً في الخلايا. وأن كذلك ممارسة التمارين الرياضية وخاصناً الثديدة والعنيفة يزيد من إنتاج الجسم من الجذور الحرة، والنتي، بدورها، يمكن أن تسبب تلف العضلات التي تتجلى بتورم أو ألم في العضلات. في حين أن ممارسة الرياضة لغرض الصحة يزيد من الدفاع الطبيعي للجسم ضد الجذور الحرة، والرياضيين الذين يشاركون في تدريبات مكثقة يستقيدون من إضافة هذه مضادات الأكسدة مع وجباتهم الغذائة. لتعمل في مثل هذه الحالة مضادات الأكسدة في مجموعة متتوعة من الطرق للحد من آثار الجذور الحرة. حجم القرص الواحد هو . . ل تحتوي العلبة على .0 قرص. $\checkmark$

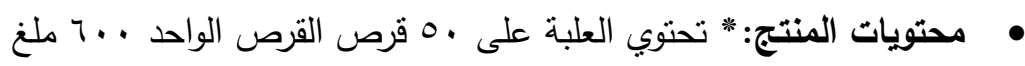

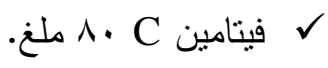

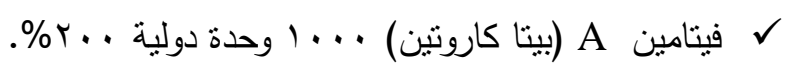

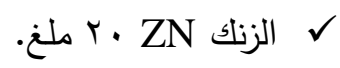


مجلة كلية التربية الرياضية - جامعة بغداد * المجلد الثلاثون* العدد الثاني * لسنة Y. IN

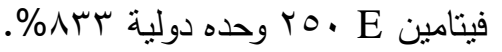

$$
\begin{aligned}
& \checkmark \\
& \checkmark
\end{aligned}
$$

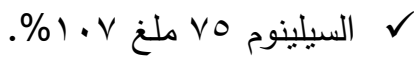

$$
\begin{aligned}
& \text { V-r الاختبارات البعدية: }
\end{aligned}
$$

بعد اكمال المدة المقررة من أمداد الرباعون بمضادات الاكسدة قام الباحث بأجراء الاختبارات البعدية بتاريخ ro/ في الساعة الخامسة عصراً (اختبارات قبل الجه) وفي الساعة السابعة وعشرون دقيقة (اختبارات بعد الجهد)، وذلك من قبل نفس الكادر المتخصص الي اجرى الاختبارات القبلية، وتم أجراء الألية العلمية لحفظ الدم حتى قياس المتغيرات، وسعى الباحث الى تطبيق جميع الظروف في أثناء هذه الاختبارات من حيث الزمان والمكان وطريقة العمل وفريق العمل المساعد وطريقة تتفيذ نسلسل الاختبارات بغية خلق الظروف نفسها أو ما يشابها عند الاختبارات القبلية بغية الدقة عند

$$
\text { أجراء الاختبارات البعدية. }
$$

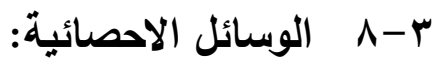
أستخدم الباحث الحقيبة الإحصائية (SPSS) لمعالجة البيانات.

؟ - المبحث الرابع: عرض النتائج وتحليلها ومناقشتها.

\begin{tabular}{|c|c|c|c|c|c|}
\hline \multicolumn{2}{|c|}{ الاختبار البعدي } & \multicolumn{2}{|c|}{ الاختبار القبلي } & \multirow{2}{*}{ وحدة القياس } & \multirow{2}{*}{ المتغيرات } \\
\hline$\varepsilon$ & سنَ س & $\varepsilon$ & سنَ سن & & \\
\hline 9.39605 & 41.4286 & 8.97085 & 48.1429 & مايكرو غرام/لتز & الكولاجين قبل الجهد \\
\hline 9.93311 & 63.0000 & 8.21439 & 74.1429 & مايكرو غرام/لتز & الكولاجين بعد الجهد \\
\hline
\end{tabular}

(1) (الجدول (1)

يبين الأوساط الحسابية والانحرافات المعيارية في متغير (الكولاجين) قيد البحث في نتائج الاختبارين القبلي والبعدي 
مجلة كلية التربية الرياضية - جامعة بغداد ** المجلد الثلاثن ** العدد الثاني * لسنة

Y. IN

الجدول (r)

يبين فرق الأوساط الحسابية وانحرافه المعياري وقيمة (t) المحسوية ودلالة الفروق بين نتائج الاختبارين القبلي والبعدي في متغيرات (الكوجين) قيا البحث

\begin{tabular}{|c|c|c|c|c|c|c|}
\hline دلالة الفروق & مستوى الخطأ & المحسوية & ع ف & فَن & وحدة القياس & المتغيرات \\
\hline معنوي & .000 & 23.500 & .75593 & 6.71429 & مايكرو غرام/لتز & الكولاجين قبل الجهد \\
\hline معنوي & .001 & 6.569 & 4.48808 & 11.14286 & مايكرو غرام/لتز & الكولاجين بعدالجهد \\
\hline
\end{tabular}

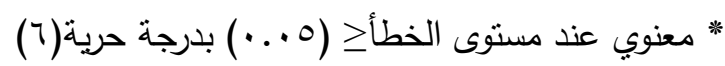

المناقشة:

من خلال القيم الواردة في الجدول رقم (1) تنين لنا أن مستوى تركيز الكولاجين (Collagen) في الاختبار القبلي (قبل الجهد) كان (48.1429) وفي الاختبار البعدي (قبل الجهد) (41.4286)، وفي الاختبار القبلي (بعد الجه) كان (74.1429) وفي الاختبار البعدي (بعد الجه) اصبح (63.0000)، وأن القيمة الطبيعية لمؤشر الكولاجين في جسم الانسان تتراوح بين (18.0 × 57.7)، فظهرت لنا معنوية الفروق لأحدى مؤشرات التلف العضلي وهو الكولاجين العضلي في الاختبارين القبلي والبعدي في كلتا الاختبارين (قبل الجهر ، بعد الجه)، ويعزو الباحث ارتفاع نسب (Collagen) الكولاجين في الدم الى التدريب المكثق عالي الثدة، بما أن الكولاجين يدخل في تركيب الانسجة العضلية، لان الكولاجين عبارة عن مادة بروتينيّة توجد في العضلات، الغضاريف، الجلد والأنسجة ويربط بعضها ببعض وان خروجه وزيادة نسبته يعد دليل على وجود خلل في هذه الانسجة والعضلات بسبب الثندة العالية والوزن المرفوع من الرباعين خلال الوحدة التدريبية وعدم توفر وسائل الاستشفاء والاسترخاء البسيطة بعد الوحدة التدريبية ومنها (حمامات السباحة) وغيرها من الوسائل المساعدة التي تساهم مساهمة فعاله في تسريع حالة الاستشفاء، وحتى وأن كان الرياضيون هم من الرياضيون النخبة، حيث يثير ابو العلاو عمر شكري (1: 7؟) الى أنه " قد أظهرت البحوث أن تدريبات التحمل والقوة يلقيان عبئ كبير على الآليات المضادة للأكسدة في الدم والخلايا التي تعمل على حماية الجسم من الجذور الحرة والتلف التابع لها، حيث يصحب التدريبات البدنية العنيفة تلف عضلي حتى في الرياضيين ذو المستوى العالي من التنريب"، و ويؤكد هذا الاتجاه (سيرفيللين G واخرون)(10: 1 (1) بأن الانسجة العضلية تتلف بعد التدريب المكثف لفترات طويلة كنتيجة للعوامل الميكانيكية والايضية وتظهر في مصل الدم الانزيمات والبروتينات التي تدل على ذلك وهي احدى علامات الحالة الوظيفية للأنسجة العضلية. ويعزو الباحث معنوية الفروق بين الاختبارين القبلي والبعدي الى تقليل نسبة الكولاجين في الدم نتيجة برنامج الامداد بمضادات الاكسدة الذي أثر تأثيراً ايجابياً في حماية الأنسجة العضلية من التلف او التقليل منه، 
لأنه احتوى على فيتامين (C)الذي يكون المسؤول على تقوية الخلايا بعضها مع بعض ومنعها من التلف، أذ يذكر نديم

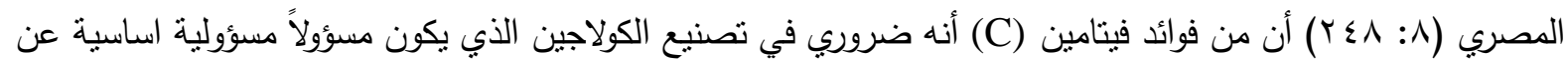
ترابط الخلايا ببعضها البعض ومنعها من التلف. ويرجح الباحث هذا التحسن في مؤشر الكولاجين الى تأثثر مضادات الاكسدة الاخرى ومنها السيلينيوم لما له من أهمية في حماية الانسجة العضلية للرباعين من التلف وهذا ما اشار اليه ابو العلا عبد الفتاح(r: (YV) "أن مركب السيلينيوم مركب كيميائي يلعب دوراً فعالاً ومهم كمضاد لعميات الاكسدة، حيث أنه يخفض من ضغوط الاكسدة والتلف العضلي الذي يسببه التدريب ذو الثدة العالية.

ويرى الباحث بما أن الياف الكولاجين (Collagen Fibers) وهي ألياف قوية تنتظم في حزم كبيرة وقابلة للانثاء وتكتسب قوتها من وجود مادة الكولاجين وتوجد في الأوتار (تربط العضلات بالعظام) والأربطة (تربط العظم بالعظم)، فأن مضادات الاكسدة لها الدور الكبير في اعادة الانسجة التالفة جراء التنريب عالي الثدة، أذ يقول نديم

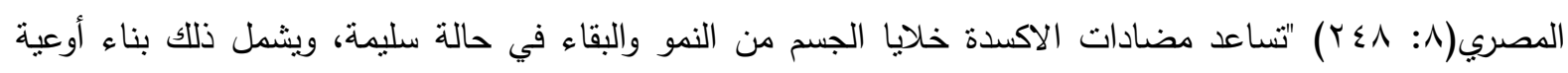
دموية سليمة، ومفاصل سليمة، ونسيج ضام سليم، وأربطة سليمة و يسرع التئام الجروح وترميم النسيج". ويذكر جلال

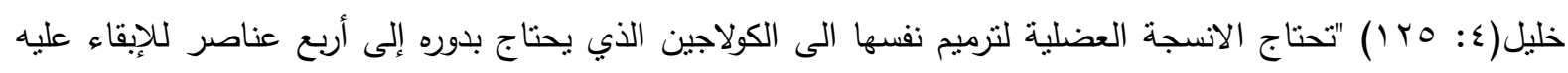
حيويا في الجسم وهي الفيتامينات A,C,E, والسيلينيوم، ويستعمل الزنك في شفاء الجروح، فهو يساعد على التئام الجروح سريعاً.".

ويؤكد هذا الكلام جبار رحيمة(س: 1971) حيث يقول " أن فيتامين (C) ضروري لتكوين الياف النسيج

الضام فهو يؤثر على عملية صنع بروتين الانسجة الضامة (الكولاجين).

ه - المبحث الخامس: الإستتتاجات والتوصيات.

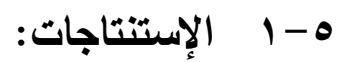

إنَّ الامداد بمضادات الاكسدة تسهم في تقليل نسبة الكولاجين في الدم وهو أحد مؤشرات التلف العضلي في

الاختبارين قبل الجهر وبعد الجهـ.

r-0

من خلال الإستتناجات التي توصل اليها الباحث يوصي بما يأتي:

ا. . عمل فحوصات الدم الدورية الى الرياضين لمراقبة التغير الحاصل في المؤشرات البيوكيميائية لغرض السلامة الصحية للرياضين.

r. ـ الامداد بمضادات الاكسدة الى الرياضين في فعاليات مختلفة قبل التدريب وبعده لارتقاء بمستوى الرياضي من ناحية المؤشرات البيوكيميائية. 
مجلة كلية التربية الرياضية - جامعة بغداد ** المجلد الثلاثون * العدد الثاني ** لسنة

$$
r \text { r I }
$$

ب. يوصي الباحث بزيادة المدة الزمنية لعمل التجربة للحصول على تطور أفضل في متغيرات البحث وخصوصاً مع

$$
\text { عينات من مستوى عالٍٍ. }
$$

ع. أجراء بحوث مشابهة لمؤشرات بيوكيميائية وفسيولوجية أخرى ومعرفة التطور الحاصل باستخدام مضادات الاكسدة

$$
\text { نفسها قيد الدراسة. }
$$

ه. استخدام نوع اخر من مضادات الاكسدة لقياس المؤشرات البيوكيميائية والفسيولوجية قيد الدراسة.

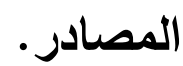

ا. ابو العلا احمد عبد الفتاح، عمر شكري عمر : الاداء الرياضي الامن والثقوق الطليقة، مضادات الاكسدة، طا،

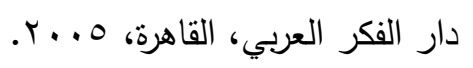

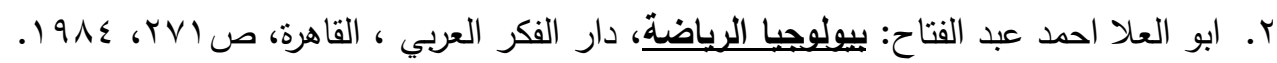

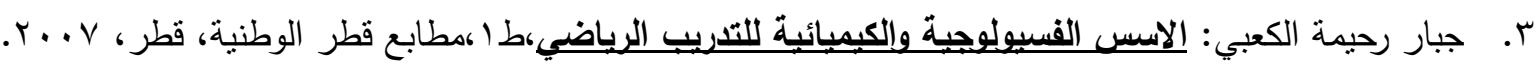
ـ. جلال خليل المخلالتي: التظذية وصحة الانسان، طب، دار الثواف للنشر والتوزيع، المملكة العربية السعودية،

ه. ديوبولد، فان دالين: مناهج البحث في التربية وعلم النفس، (ترجمة) محمد نبيل (واخرون)، القاهرة، مكتبة الانجلو

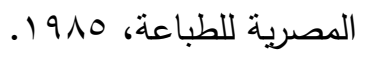

ד. عبد اله عبد الرحمن الكندري ومحد عبد الدايم: مدخل الى مناهج البحث العلمي في التربية والعلوم الانسانية، طب، الكويت، مطبعة الفلاح للنشر والتوزيع، 1999 ـ V. عبد المنعم محمد الأعسر : أسس الكبيباء الحيوية، المجلد الاول، المكتبة الاكاديمية، الجيزة، جمهورية مصر

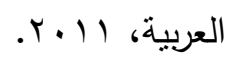

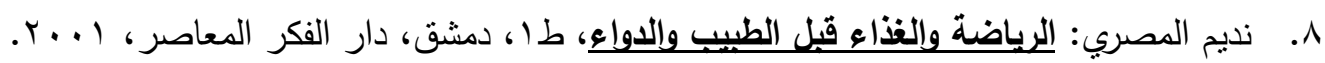

9. Lohuis ،TD؛ Harlow ‘HJ $₫$ Beck ،TD, Comparative Biochemistry and Physiology Part

B: Biochemistry and Molecular Biology, 2007 ‘Pages 20-28. 
مجلة كلية التربية الرياضية - جامعة بغداد * المجلد الثلاثون * العدد الثاني ** لسنة $r+11$

10. Ekkekakis P, Hall Ee, Petruzello Sj. Intensity Of Acute Exercise And Affect: A Critical Reaxamination Of The Dose-Response Relationship .Med Sci Sports,2001,p63.

11. Packer L. Oxidants, Antioxidant Nutrients And The Athlete. J Sports ,ci,1997,p353-416. 12. Walter de Gruyter: Biochemical markers of muscular damage, Berlin. New York,2010,p179-180.

13. Handelman G.J:Evaluation of oxidant stress in dialysis pediments. Blood purify, 18,2000 .

14. Kanter. M.(1994): " Free Radicalsexercise and Antioxidants supply".Int. sport Natr.

15. Cervellin G, Comelli I, Lippi G. Rhabdomyolysis: historical background, clinical, diagnostic and therapeutic features. Clin Chem Lab Med 2010;48:In press. 